\title{
Going virtual and going wide: comparing Team-Based Learning in-class versus online and across disciplines
}

\author{
Elsa Costa e Silva ${ }^{1}$ (1) Teresa Lino-Neto ${ }^{2}$ (1) - Eugénia Ribeiro ${ }^{3}$. \\ Miguel Rocha ${ }^{4}\left(\mathbb{D} \cdot\right.$ Manuel João Costa $^{5}(\mathbb{C}$
}

Received: 9 April 2021 / Accepted: 19 July 2021 / Published online: 16 August 2021

(C) The Author(s), under exclusive licence to Springer Science+Business Media, LLC, part of Springer Nature 2021

\begin{abstract}
Team-based learning (TBL) is an active learning pedagogy developed for in-class sessions and based on the collaborative work of small groups of students. The increasing push to online and blended learning has enhanced the need to expand this pedagogy to a virtual environment, but little evidence has been produced on how students accept online synchronous sessions of TBL. The purpose of this study, that relies on 427 responses, is to present a comparative perspective of traditional in-class versus adapted fully synchronous online TBL and across different disciplinary fields. Students of two different academic years and different programs were surveyed for their acceptance of TBL. They were invited to answer closed-ended questions focused on their engagement in all TBL learning process and the final outcomes provided. Results obtained from this unique comparative study revealed a wide approval of TBL, regardless of the environment (online or in-class TBL sessions), scientific area of courses and student gender. The acceptance of fully online TBL sessions, in a similar way as traditional in-class sessions, could be a rationale for giving more use to the 'virtual' context. Other results corroborated previous researches on TBL, such the need of student awareness of TBL benefits to get more engaged in the process or the impact of student activities overload on the TBL process. Implications are informative for pedagogical practice.
\end{abstract}

Keywords Team-based learning · Collaborative groups · Online learning · Gender · Disciplines

Elsa Costa e Silva

elsa.silva@ics.uminho.pt

Extended author information available on the last page of the article 


\section{Team-based learning in the online environment: does it work?}

Higher Education institutions are increasingly looking for effective engaging pedagogies across disciplines to involve students in active learning (Moore et al. 2007). Active learning pedagogies reduce college drop-out, promote better student attitudes and improve both critical thinking and academic performance of students (August et al. 2002; Bonwell \& Eison 1991; Braxton et al. 2000; Freeman et al. 2014; Prince 2004). Most of active learning approaches have been developed for the face-to-face environment, but there is an increased need to adapt to blended and online learning. However, online learning poses new challenges as it is perceived as not suitable for all students (Kauffman 2015), with variables such as gender impacting the perception (Burhanuddin et al. 2020). One major issue in the field of online active learning is the use of technology-based distance education that may hamper students' engagement and fruitful discussion in collaborative groups (Vuopala et al. 2016). This exploratory study analyzes the perception of students of Team-Based Learning (TBL), an active learning pedagogy based on the collaborative work of small groups of students, by focusing on an understudied approach: the delivery of content modules in synchronous versus in-class sessions in a cross-discipline comparative perspective.

TBL is a pedagogy that promotes active and cooperative learning. As part of the learning process, this strategy is characterized by the use of in-class team work that requires the application of knowledge by students. TBL successfully promotes the students' engagement and satisfaction with the learning process (Haidet et al. 2014; Sweet \& Michaelsen 2012). However, most studies on TBL are restricted to smallscale face-to-face and single-course experiences. A broader assessment of TBL is thus lacking to widen the possibility of its application to synchronous online classes and to a larger disciplinary scope. Up to now, the implementation of online strategies for TBL has been scarcely described in the literature, due to the well-recognized limitations of collaborative online work between students. Given the recent pandemic Covid-19 that pushed universities to online and virtual teaching at unprecedented and unseen levels, a new urge for pedagogies fit for online learning resonated in higher education institutions. In any case, this move to the virtual environment should not endanger the benefits of active learning. In that sense, a comparison of students' perception of face-to-face and online synchronous TBL sessions would contribute to a better understanding of how to expand TBL implementation. Also, a comparative approach in terms of different scientific disciplines and students' gender could provide news insights on the acceptance of this pedagogy. The aim of this article is, thus, to provide a broader comprehension of TBL in a comparative perspective that can assess the suitability to the online environment and to different disciplinary courses. Our study involved 319 pre- and postgraduate students, taught in different programs from the University of Minho (Portugal), from Engineering, Social and Natural Sciences, in 2018/2019 and 2019/2020. 


\section{Team-based learning}

TBL is an instructional approach that has been recognized to better prepare students for the current professional world challenges (Cheng et al. 2014; Currey et al. 2018; Frame et al. 2015; Hills 2001). TBL is a structured, active and collaborative learning methodology developed by Larry Michaelsen (Michaelsen \& Sweet 2004) for management courses in the early $1980 \mathrm{~s}$. TBL has gained particular acceptance in medicine and health sciences education, while fewer experiences in other disciplines have been described (Parmelee \& Hudes 2012; Sweet \& Michelsen 2012; Travis et al 2016). TBL assigns different roles to both teachers and learners. Teachers become learning facilitators, rather than content transmitters. They are responsible for developing a meaningful assessment process and, if needed, act as a team-interaction challenger.

TBL proceeds through a four-stage process. The first stage is previous to the class, in which students acquire introductory knowledge from reading and consulting study materials (such as textbooks, scientific articles, videos, podcasts, etc.). Teachers are implicated in the process by providing all supportive materials for student's preparation in a flipped classroom strategy. In a second stage, already in class, the previous preparation of students is tested through a readiness assurance process, comprising two different moments: an individual assessment (IRA, individual readiness assurance), followed by a team work that retakes the same assessment. Given that the team must agree on one common answer for tested items, students must engage in meaningful discussions in order to reach a consensus. This second moment allows students to compare answers with their colleagues and negotiate a single group answer for each question. This process gives them the opportunity to engage in peer learning for clarifying any content that may still raise doubts. The same assessment is then discussed between teams and the teacher, who can offer a more oriented explanation, based on the discussion he/she observed during the team work. Finally, new problems of higher complexity demand are given to students, to which they can apply the knowledge developed with their peers. Taken together, this methodology thus enhances collaborative work and problem-solving skills.

Wallace et al (2014) argued that TBL is an effective, in-class, and instructional-strategy that facilitates the development of student's expertise. In this strategy, the content acquisition is enhanced from the pre-class study, while the majority of class time is used for significant learning activities. Mistakes are welcomed and regarded as "learning opportunities" and "one of the best ways of making learning efficient" (Hills 2001). In that sense, the teacher should seek student engagement and maximal participation through the creation of a learning atmosphere that is "fair and tolerant and where people can feel free to make mistakes without fear of embarrassment" (Gullo, et al. 2015, p. 823). One of the many advantages of this instructional approach is the immediate feedback students receive, first from their peers and then from the teacher. The peer review team work positively affects learning, students' capacity to direct learning and self-efficacy (Moore \& Teather 2013). TBL thus focuses on the autonomy and interdependence of students, while promoting their higher-level thinking skills. 
The traditional in-class TBL setting has been positively evaluated by students and instructors. Teachers described more self-enthusiasm and enjoyment of teaching (Kubitz 2014), while students revealed greater engagement and participation, as well as higher academic performance (Haidet et al. 2014; Kubitz 2014). Students also identified critical thinking, problem-solving and deeper understanding as beneficial aspects of TBL (Espey 2018; Styron \& Styron 2014). A systematic review performed by Swanson et al. (2019) reported that students find TBL interesting, allowing for a deeper understanding of contents, and preparing them more effectively for assessment and course performance. Some less positive attitudes towards TBL have been reported by students in their final semesters and in students that claim being overloaded by program activities (Pires et al. 2020). Nonetheless, more research is needed to evaluate how students perceive TBL in an online environment and if different scientific disciplines or student gender influence their acceptance.

\section{Technology, disciplines and gender in TBL}

Over the last years, higher education institutions have been moving some of their teaching and learning processes to an online environment. This has put a new pressure on in-class active learning strategies that had to be adapted to the 'virtual' environment. Although some research has been conducted on the use of technology for distance education in a context of active learning, the field is still underdeveloped, namely in what concerns methodologies such as TBL. The question on whether the students experience the same benefits of TBL in synchronous sessions from online TBL sessions remains largely unanswered. As stated by Goh et al., (2020, p. 2), "TBL in online learning environments is still in its infancy". In a context of unexpected closure of higher education institutions, the assessment of the effectiveness of fully online active methodologies acquired new relevance. Practitioners need to know whether their instructional approach can be used without impairing student experience (Hew et al. 2020).

Although the use of technology has promoted better student engagement (Plump \& LaRosa 2017) and provide useful mechanisms for a regular feedback to students (Poirier \& Feldman 2007), these benefits were only reported using in-class strategies. When used for distance learning, technology can impact student ability to concentrate (Tsai 2011) or even impair the learning experience if completely or mostly substitute teacher contact (McLoughlin \& Luca 2006; Saunders \& Klemming 2003). However, if fully aligned with the teaching purposes, the technology use in higher education has been shown to significantly improve student learning (Turney et al. 2009). However, the use of technology for online synchronous collaborative sessions induces more informal and less metacognitive, theory-based knowledge conversation between students, as discussions remain more superficial (Hou \& Wu 2011; Vuopala et al. 2016).

Calling for research that can discern the impact of technology into TBL on student preference, River et al. (2016) found that students experienced mixed feelings regarding the use of TBL with blended technology (combining face-to-face teaching with online learning experiences), but in general they reported less satisfaction 
with this scenario. TBL has mainly been used for in-class interactions and has not been considered to be easily adapted to non-presential learning (Goh et al. 2020). Some experiences on TBL adaptation to the online environment have been mainly developed by incorporating asynchronous moments, such as the teamwork of different groups (Cabrera et al. 2017; Gomez et al. 2020; Samuel \& Hindon 2010). Nonetheless, to the best of our knowledge, the impact of fully online TBL synchronous classes on students has not been assessed. One of the major predicted obstacles is the difficulty of student-to-student interaction and consequent impairment of collaborative work, which is critical for the TBL methodology. Because experiences in online TBL and, especially in fully synchronous online TBL, are not, until now, frequent, there is no conclusive evidence on the benefits or disadvantages of online versus in-class TBL. One of the few studies that compared both modalities found no difference in the students' performance, but students reported to prefer in-class TBL to online TBL (DeMasi et al. 2019).

The perception of online learning in terms of student acceptance, motivation, and satisfaction is also influenced by gender (Burhanuddin et al. 2020). This adds to other known roles of gender in the learning process, engagement and motivation for higher education in general (Barone 2011; Conger \& Long 2010; Grebennikov \& Skaines 2009; Jacobs 1996; Pirmohamed et al. 2017) or for the particular context of active learning methodologies (Colbeck et al. 2001; Opdecam et al. 2014). The commitment to university life seems to be more evident in females than in males, as women spend more time preparing for classes, studying and reading (Grebennikov \& Skaines 2009). Also, females reveal a preference for collaborative learning over their male counterparts (Lundeberg \& Moch 1995; Opdecam et al. 2014; Stump et al. 2011), who are found to be more competitive and individualists (Cabrera et al. 2002). Available studies on TBL that have controlled their results for gender found small or no differences (Espey 2018; Hettler 2015), which call for a better understanding on how gender impacts the overall acceptance of this instructional approach.

Another concern in research addressing flipped classroom strategies (in which TBL is included), which echoes the broader research in higher education, is its siloed nature. The absence of shared knowledge, beyond the clusters of educational technology and of the Science, Technology, Engineering, Mathematics and Medicine (STEMM) areas, limits cases within subject areas or courses (Lundin et al. 2018). This also applies to the particular case of TBL, in which there is a relevant absence of broader disciplinary studies. A comparison between disciplinary areas would be crucial given the perception that TBL may not be suitable for all disciplines and that some could have higher difficulties to implement this instructional approach (Bulanda \& Frye 2020; Lewis et al. 2019; Nanes 2014). Broader approaches to TBL have mainly focused on the theoretical aspects of TBL implementation (Robertson \& Franchini 2014) or considering single coursesbased experiences (Sweet \& Michaelsen 2012). But, there is not a comparative perspective between multiple disciplines (Styron \& Styron 2014). Even when general skills (such as critical thinking) or the impact of new technologies (such as supportive podcasts) are studied in relation to TBL, it happens in the context of a single discipline (Espey 2018; Taylor et al. 2012). Also, Parappilly et al. (2019) conducted 
a research on students from different STEMM disciplines, but did not conclude about possible differences or similarities between them. The authors just acknowledged that TBL could be a feasible and effective method of student-focused learning within STEMM.

Research regarding the implementation of TBL has been increasing in the last decades, but most has been found in journals of higher education, concerning learning contexts of particular disciplines, such as 'Medical Teacher', 'Journal of Nursing Education' or the 'American Journal of Pharmaceutical Education'. Higher education journals of a broader disciplinary appeal have not frequently addressed TBL. One of the reasons is that TBL studies are rarely performed comparing students from different disciplinary courses.

\section{Present study}

The current paper reports on a comparative study aiming to describe the students' perceptions of TBL impact on the learning process, comparing in-class versus online sessions, different scientific disciplines, and gender. The following research questions were posed:

1 What are the common and divergent factors on the students' evaluation when comparing face-to-face and online TBL synchronous classes?

2 What are the common and divergent factors on the students' evaluation of TBL classes when comparing different scientific disciplines?

3 How do students evaluate TBL classes depending on gender?

44 How do students perceive the impact of TBL classes on their learning process, including aspects such as collaborative learning, critical thinking, learning by mistake and exam readiness?

Context and TBL adaption This study was developed in the context of a Faculty Learning Community from the University of Minho. In the beginning of 2018, teachers from different programs of the University of Minho, sharing a common interest in developing proficiency and implementing TBL format in their classes, joined energies to create the community of practice TBL-Now. Usually, the members of this community meet once a month to share their experiences using TBL, to discuss appropriate adjustments to specific scientific disciplines or contents, and to collaborate on develop resources and instruments to assess teachers and students' perceptions of TBL classes. A small group of teachers within this community of practice, belonging to different scientific areas-namely: Social Sciences (Psychology; Communication Sciences), Natural Sciences (Biological Sciences) and Engineering (Biomedical Engineering and Bioinformatics)—started a focused and exploratory study on students' perception of TBL.

In the context of the COVID-19 pandemic, Portugal declared the state of emergency on March $18^{\text {th }} 2020$. Among the measures aimed to contain the spread of the infection, and in accordance with government guidelines, the University of Minho 
was the first Portuguese university to move all classes from face-to-face to online format. The sudden and imperative change in classes' organization, with the consequent immediate adaptation to a new online format, challenged teachers of the community of practice TBL-Now to adjust their TBL classes to this format. Maintaining the initial technology-based delivery of study materials, the implemented adjustments were as follows: 1) instead of providing a physical (paper) individual readiness assessment (IRA), a file was made available on the E-learning platform, shortly before the TBL class, 2) when the class was opened on a videoconference platform (Blackboard Collaborate Ultra or Zoom), students completed the IRA individually, 3) instead of promoting the formation of groups in the same physical room, simultaneous conference "breakout" rooms were created on the digital platform and students were randomly assigned for team readiness assessment (TRA), 4) teachers communicated with students and stimulated groups' dynamics using the chat tool and by moving between the different conference rooms, 5) upon breakout rooms closure, all students and the teacher reunited in the main room for a global class discussion, in some cases resorting to audience response systems support, like Voxvote, to promote higher engagement, 6) the teacher summarized the main lesson's topics, and, finally, students were invited to reflect upon and apply the developed knowledge to new problems.

Participants in the current study From February 2018 to October 2020, an estimated total of 655 students and 5 teachers of the University of Minho were involved in TBL classes under the framework of this study. The number of TBL classes along the semester varied between courses (from 2 to 8 ). For the purpose of this study, we only considered the participation of those students who completed the questionnaires after classes. Therefore, 319 students enrolled in five different courses of University of Minho participated in the current study by answering the questionnaire, corresponding to a response rate of $49 \%$ (Table 1).

Instrument and procedures. Considering the aims of the study, a survey was judged as a suitable method and students were asked to answer closed-ended questions. A questionnaire focused on the students' acceptance and participation in TBL classes, as well as of their perceptions of TBL benefits on the learning process and outcomes,

Table 1 Students participating in study by course and academic year

\begin{tabular}{|c|c|c|c|c|}
\hline & \multicolumn{2}{|l|}{ 2018-2019 } & \multicolumn{2}{|l|}{ 2019-2020 } \\
\hline & Year of program & $\begin{array}{l}\text { Number of } \\
\text { students }\end{array}$ & Year of program & $\begin{array}{l}\text { Num- } \\
\text { ber of } \\
\text { students }\end{array}$ \\
\hline Psychology $^{1}$ & 4 th & 52 & 4 th & 38 \\
\hline Communication Sciences & $3 \mathrm{rd}$ & 27 & 2nd & 36 \\
\hline Biological Sciences & $1 \mathrm{st}$ & 36 & $1 \mathrm{st}$ & 40 \\
\hline Engineering $^{1}$ & 2nd, 3rd, 4th & 56 & 2nd, 3rd, 4th & 34 \\
\hline
\end{tabular}

\footnotetext{
${ }^{1}$ In the time of the study, in Portuguese Higher Education system, master in Psychology and Engineering were integrated with graduation, meaning that the 1st year of master corresponds to the 4th year of full program
} 
was developed in the context of the TBL community of practice. This questionnaire included: a section for demographic and academic characterization, a section consisting of 8 items on students' participation and learning on TBL classes, rated on a 4-point Likert scale. Because this study purpose was to collect perception of students who had had the learning experience, the neutral point was not considered so students would be forced to judge their experience and would not have the possibility of misusing the midpoint (Chyung et al. 2017). This questionnaire was built on Google Forms. At the end of each semester, whatever the number of sessions carried out, teachers invited their students to complete the same questionnaire, informing them about the purpose. They were also informed that by deciding to answer the questionnaire they were giving their informed consent to use their data for academic research. The link of the questionnaire was made available to students on the E-learning platform. This study presents the analysis of the following questions:

a) Q1-I enjoyed the classes where TBL was used

b) Q2-I would like TBL to be used in other courses

c) Q3 - The use of TBL in this course helped me to prepare for the exam

d) Q4-The errors I made, when answering TBL questions, allowed me to learn

e) Q5-The TBL sessions contributed significantly to my critical thinking

f) Q6-In the TBL sessions, I participated actively in my team's work

g) Q7-The work within teams contributed significantly to my learning process

h) Q8-I prepared in advance to the sessions, reading the materials made available

For the purpose of this study, we considered the following independent variables: gender, course, and sessions modality (online versus in-class TBL). The dependent variables considered in this study were: perception over TBL (addressed by Q1 and Q2), perception about benefits of TBL in what concerns learning by error, critical thinking, exam preparedness and collaborative work (addressed by questions Q3, Q4, Q5 and Q7) and level of engagement of students in the process, namely in collaborative work and previous preparation (addressed by questions Q6 and Q8). Students responded in 4 levels of agreement ("completely disagree", "disagree", "agree" and "completely agree"), with the additional possibility of not replying to specific questions. These four levels were coded with numerical integer values in a scale of 1 ("completely disagree") to 4 ("completely agree").

Results were processed in $\mathrm{R}$ for statistical treatment. The analysis of sessions context (online versus in-class) and of student gender was performed with a Wilcoxon test (non-parametric) to assess if differences were statistically significant. The test $p$-values were adjusted using the False Discovery Rate (FDR, Benjamini-Hochberg) method, with a significance level of $99 \%$. The analysis of students' perception in different disciplines was performed using the Kruskal-Wallis test (non-parametric), again using FDR for multiple testing correction. 


\section{Results}

A total of 427 responses were collected (Fig. 1), with the following distribution among disciplines: 117 of Biological Sciences; 105 of Communication Sciences, 80 of Engineering and 125 of Psychology. Of the total responses, 287 (67.2\%) corresponded to in-class TBL and 140 (32.8\%) to online TBL. In 2018/19, 171 responses were collected, a number that increased to 256 in 2019/2020. The difference between the number of students involved and the number of responses is due to the fact that some students responded for both online and in-class sessions, being recorded both responses for those students. Our sample comprised responses from 340 female students $(79.6 \%)$ and 87 from male students (20.4\%). The majority of our respondents were students in their Master's first year (160), followed by students in the first year of graduation (117). We also surveyed students in their second (86) and third (64) graduation year. Figure 1 summarizes the main metadata variables characterizing the sample.

In general, the inquired students reported a very positive perception of TBL, of its benefits on learning process and of their participation (Table 2; Fig. 2). Overall, students seem to value the benefits of this instructional approach, such as the enhancement of critical thinking and the contribution of errors. We found a clear predominance of positive responses, which is in line with the results from reviewed literature on TBL implementation (e.g. Haidet 2014).

Questions Q2 (use of TBL in other courses) and Q8 (previous preparation for the sessions) presented the highest percentage of negative responses (but still below 30\%). On the other hand, question Q4 (related to the contribution

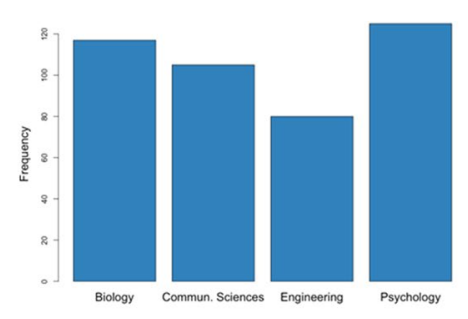

a) Field of study
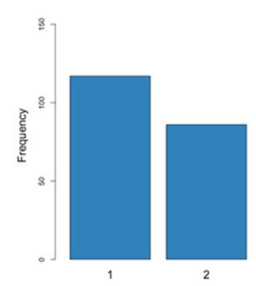

b) Year of study

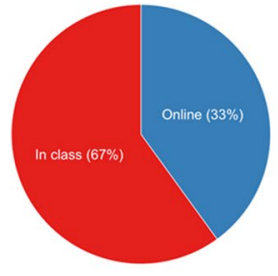

c) Type of session

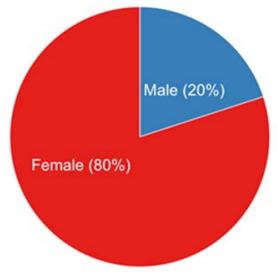

d) Gender

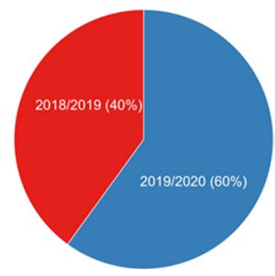

e) School year

Fig. 1 Overall characterization of the sample, including the following metadata variables: a field of study; b year of study; c type of session (online versus in-class); d gender; e school year 
Table 2 Student's responses to the questionnaire completed at the end of courses, for evaluating the acceptance and participation in TBL sessions, as well as TBL impact on the learning process. $(N=427)$

Question

$\begin{array}{ll}\begin{array}{l}\text { Mean of } \\ \text { responses } \\ \text { (scale 1-4) }\end{array} & \begin{array}{l}\% \text { of positive } \\ \text { responses }\end{array}\end{array}$

Q1- I enjoyed the classes where TBL was used

Q2- I would like TBL to be used in other courses

3.007

72.8

Q3- The use of TBL in this course helped me to prepare for the exam

3.214

84.3

Q4- The errors I made when answering TBL questions allowed me to learn

Q5- The TBL sessions contributed significantly to my critical thinking

Q6- In the TBL sessions, I participated actively in my group's work

Q7- The work within groups contributed significantly to my learning process

Q8- I prepared in advance to the sessions, reading the materials made available

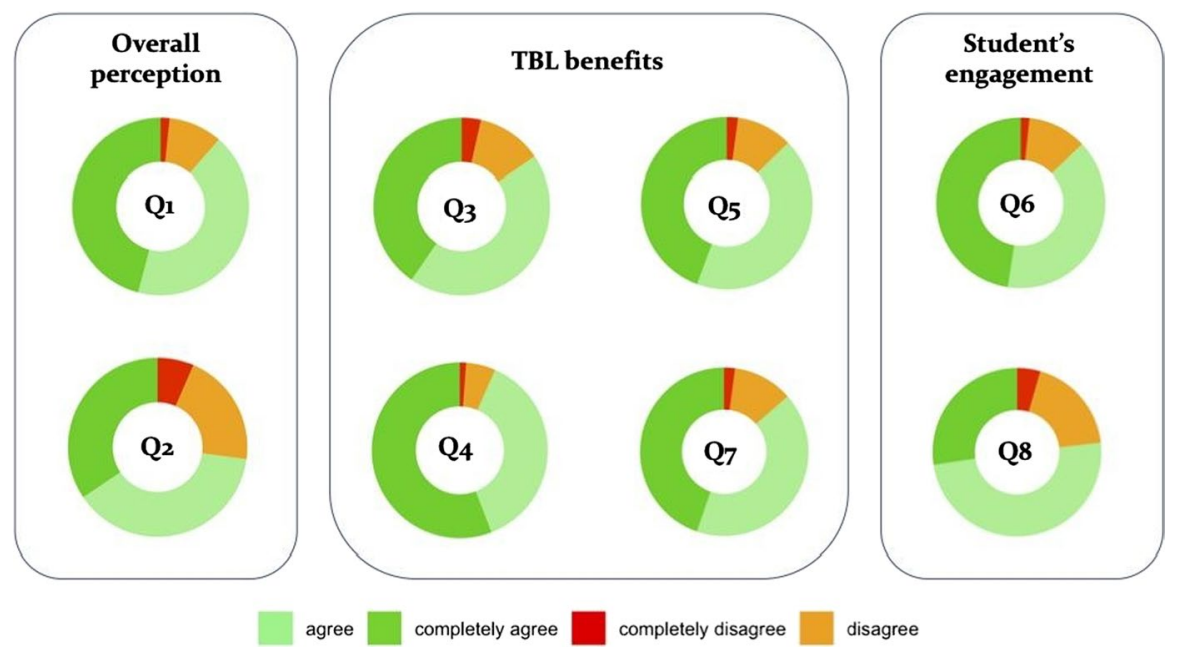

Fig. 2 Summary of the responses for each question (Q1-Q8) in the four levels

of errors to the learning process) displayed the highest percentage of positive responses and of 'completely agree' answers. Questions Q1 and Q5 (related to the overall perception of TBL and contribution of TBL to critical thinking, respectively) followed in terms of higher levels of agreement. 


\subsection{In-class versus online}

No significant differences were found in responses of students regarding the TBL in online synchronous sessions versus classic in-class TBL. The comparison of these responses revealed a high positive perception using both class contexts, showing that TBL is well accepted regardless of the modality of classes (Fig. 3). Synchronous online sessions were similarly appreciated as in-class sessions. However, online TBL presented always a slightly higher (but not significant) acceptance, except for Q6 that refers to the participation of students in team discussions. In this item, the students attributed a slightly (again not significant) higher value to in-class sessions.

The questions with higher differences are Q3, Q5 and Q8. These relate to the relevance of TBL to prepare students for the exam $(p=0.002)$, TBL as a way to promote critical thinking $(p=0.009)$, and about previous preparation for TBL sessions $(p=0.000)$, respectively. In these questions, students attributed higher values in the responses referring to online sessions. Overall, we can conclude that there are no major significant differences in the perception of online versus in-class sessions. However, students reported that online sessions prepare them better for exam and promotes their critical thinking.

\subsection{Scientific discipline}

Our results show that TBL is well accepted by students from different fields. Students from all surveyed disciplines clearly appreciated the methodology and had a
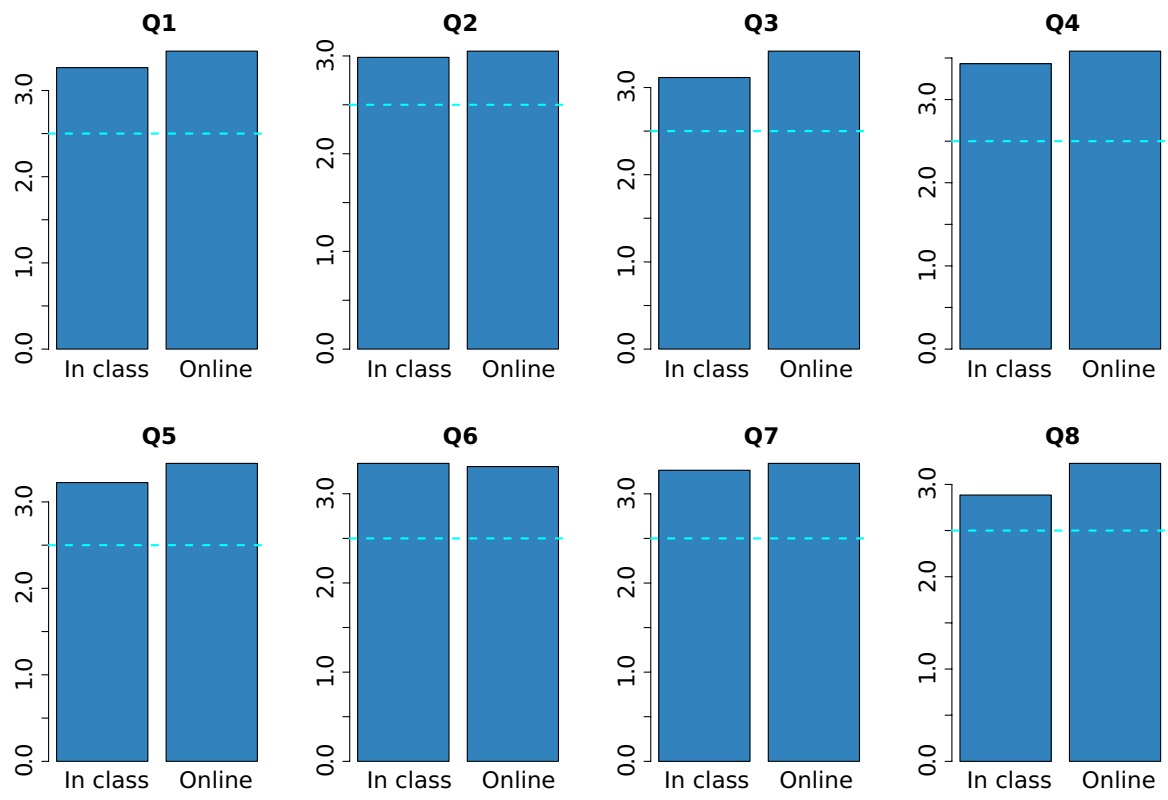

Fig. 3 Mean of the responses for each question (Q1-Q8) for in class and online sessions 
positive perception of its benefits. Indeed, although we found minor disagreements among disciplines, TBL was generally valued by students (Fig. 4). Although presenting an overall positive perspective, students of Communication Sciences showed a lower level of agreement, except when considering the engagement of students
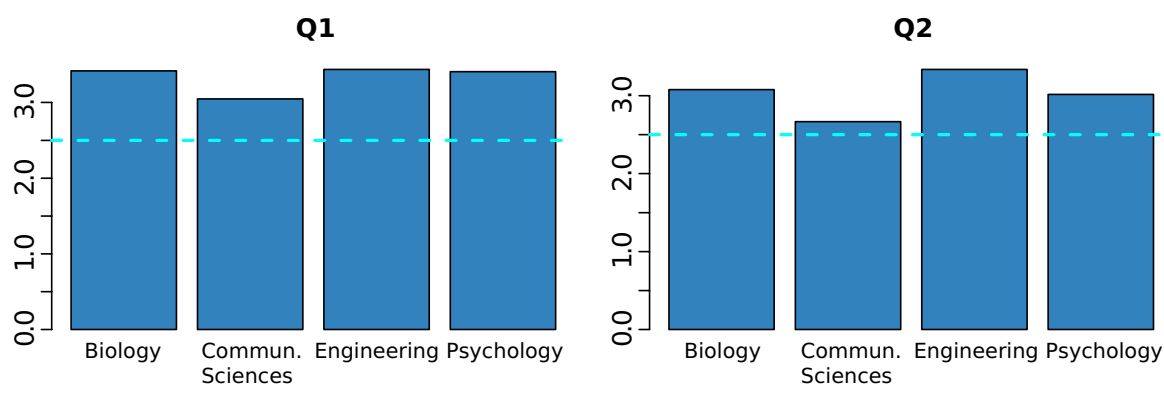

Q3
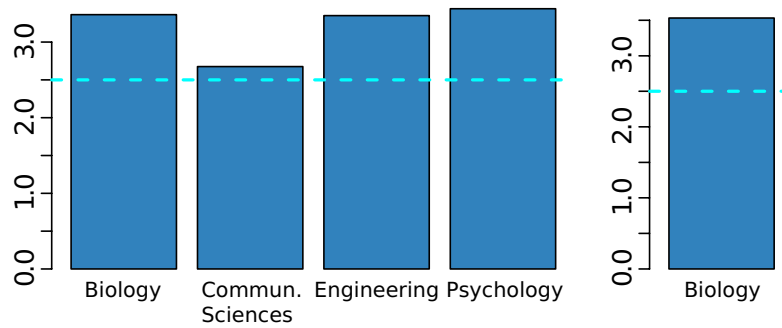

Q4

Q5
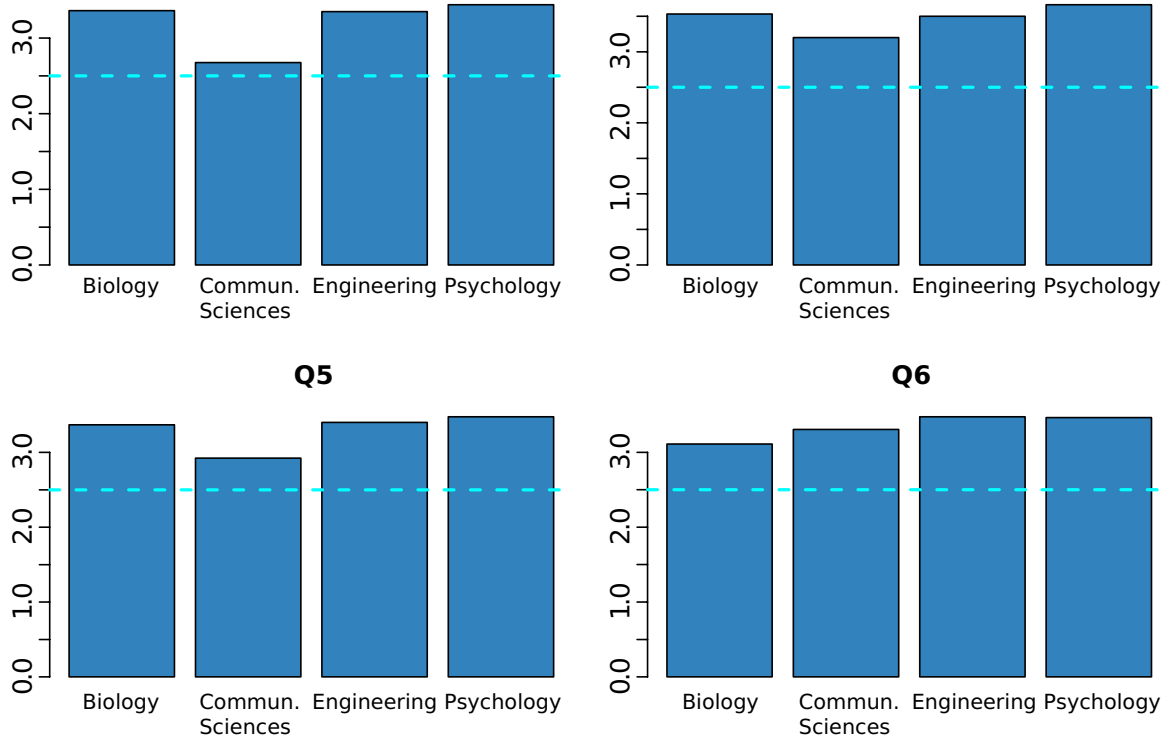

Commun. Engineering Psychology Sciences

Q7

Q8
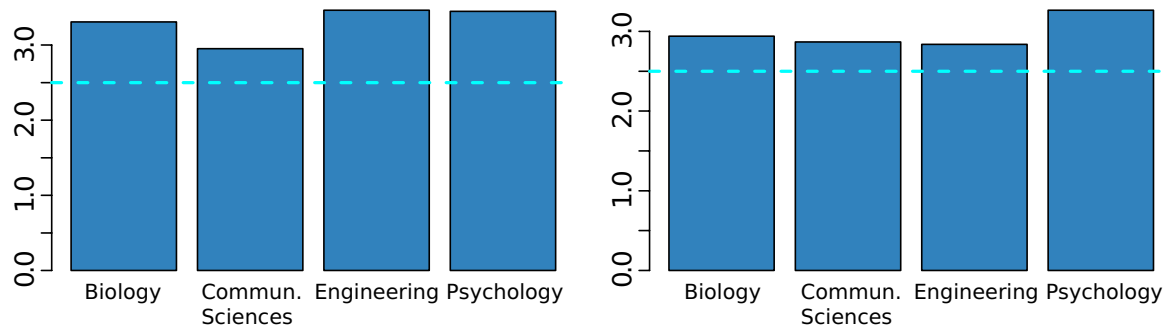

Fig. 4 Mean of the responses for each question (Q1-Q8) for the different fields of study 
(Q6 and Q8). These students particularly disagreed with the possibility of implementing TBL in other courses. The statistical analysis confirmed that discipline matters in the perception of TBL.

In order to better understand why students Communication Sciences were less favorable to TBL, we analyzed the results by school year, in order to assess if differences between disciplines held for classes from different academic years. We first split the responses by the field of study for each academic year, in order to compare the same discipline in different years. From the overall results, Communication Sciences was the only field of study where large and significant differences between school years were detected in most questions. In fact, students from the year 2019/2020 (who were attending the 2nd year of graduation) gave a significantly higher mean response level to most questions, compared to the students from 2018/2019 (who were senior students, 3th year of graduation). Only in Q4 (related with error for the learning process) and Q6 (related with student participation), there were no significant differences between school years. In the other fields, there were few differences in scattered questions, with no major significance in the overall results of the study. There were also differences in Q1 and Q2 for the students of Psychology and in Q8 for Biological Sciences students. No significant differences were found in engineering students.

\subsection{Student gender}

Gender did not prove to be a significant variable for explaining TBL acceptance. Except for the questions related to the engagement in TBL process (Q6 and Q8), male students seemed to have a slightly (although non-significant) more positive perception of TBL and of its benefits. Female students revealed to be more engaged in previously preparing TBL sessions then their male counterparts $(\mathrm{Q} 8, p=0.000)$.

\subsection{Overall acceptance}

In order to better understand the perception of students regarding the methodology, we analyzed the relationship between their overall acceptance and their level of agreement regarding questions that approached the benefits of TBL (Q3-5, Q7) and the ones that reported the level of engagement of students in the process (Q6, Q8). We created two subsets of data, according to the positive or negative responses to Q1. We calculated the mean of responses to questions from Q3 to Q8 for both groups and the difference of these means. We then performed a statistical test to compare the responses in each group. For all the questions, the means were significantly different for both groups, although differences were less pronounced in questions related to their participation and engagement in the process. This shows that students with a negative perception of the methodology also have a negative impression about its potential advantages. In any case, these students still participated in the group sessions and prepared themselves before sessions (even though at a lesser level than students that appreciated the methodology). 


\section{Discussion}

Higher education institutions are enduring new challenges posed by the pandemic, which made them rethink the role of technology and of distance learning. In particular, the active learning methods were faced with the difficulty of replicating in-class interaction and dynamics, thus possibly troubling the engagement and acceptance of students. Nonetheless, our study shows that TBL online synchronous sessions share the same level of approval as traditional in-class sessions. Indeed, this instructional approach could be a solid option for instructors looking for active learning settings in the context of 'virtual' classrooms. We developed an adaption of TBL to the online environment, particularly ensuring ways to maintain the contact between teachers and students and using technological resources to promote their engagement. In this context, the use of TBL allowed promoting dynamic sessions, that kept students motivated and prevented some pitfalls associated with online courses, such as the lack of concentration (Tsai 2011). The use of technology in this case, because fully aligned with the teaching aims (Turney et al. 2009) and not a means in itself, helped to promote a fruitful engagement of students.

This research provided a unique comparative approach to TBL that aimed at exploring the acceptance of this instructional approach, regarding its application to different scientific disciplines, student gender and environment. While several studies have provided relevant insights to TBL, these were mainly single course based and did not compare perceptions across student gender. Previous studies have also not considered different modalities of TBL sessions (in-class or online) and mainly used a siloed approach that hinders its broader appeal. This study provides evidence-based support of this instructional approach, regardless of the scientific area and gender. Students particularly agreed to the fact that TBL enhanced their critical thinking skills and that errors they made in the process were helpful to a better understanding of the contents. In contrast with some evidences that suggest online synchronous sessions may 'damage' the quality of the group discussion (Vuopala et al. 2016), in the context of online TBL, the students showed equal satisfaction with the collaborative group discussion.

Most students reported a positive evaluation of TBL classes. Compared to those who were less favorable toward TBL classes, these students were more favorable in terms of both the perception of benefits and engagement in the learning process. These results suggest that, in general, students perceived TBL classes as successful in their main purpose of promoting collaborative learning. Critical aspects of TBL, like critical thinking, learning by mistakes, and exam readiness, were positively evaluated by students as TBL benefits. Students who reported less enthusiasm regarding this methodology, although stating that they participated in the process (namely in group discussion and in previous preparation), are also the ones who perceived fewer benefits to the methodology. These results are in line with the findings from previous research, suggesting that students need to understand the value and benefits of this kind of approach to appreciate and enjoy the collaborative learning experience (Hillyard et al. 2010; Johnson \& Johnson 2009; Lee et al. 2016). An implication of this finding is that teachers could enhance the engagement of 
less enthusiastic students by explaining, previous to implementing TBL, some of the proven advantages of the pedagogy and of collaborative work (Clinton \& Kelly 2020).

Considering the comparison of TBL approaches among different disciplines, although a mainly positive perception has been detected, students of Communication Sciences from 2018/19 revealed a lower level of agreement. As this was the only subsample that included senior students $\left(3^{\text {th }}\right.$ year, corresponding to the final year of graduation), we speculate that they were less receptive to TBL because they were more focused on concluding their final project and graduation. This hypothesis is in line with Pires et al. (2020) that discussed the impact of student overload of activities on the acceptance of more active and collaborative instructional approaches because of the higher preparation burden they demand. This suggests that teachers should work together with other teachers of the same graduation to assess the workload, hence guaranteeing that favorable conditions to students are in place.

Female and male students equally approved TBL methodology. In spite of literature reporting that males are less favorable of collaborative methodologies (Cabrera et al. 2002), our results did not find evidence that this applies to TBL. When students were asked if they would like to experience TBL in other courses, there was even a slightly higher agreement of male students. When comparing with females, the only significant difference was found in the preparation for TBL sessions, self-reported to be higher by female students. This is in line with the literature that argues that female students devote more time to the study and preparation of classes (Grebennikov \& Skaines 2009). But this circumstance did not seem to have an impact on the overall acceptance of the methodology.

Even though, to the best of our knowledge, this is a unique study in terms of the employed comparative approach, this research only analyzed four scientific areas, a limited number of courses and students within each area. A broader range of disciplines (for instance, from Humanities or Law) could help to consolidate our findings. On the other hand, our comparative study regarding the use of online sessions took place in a very particular circumstance (during the first lockdown induced by the pandemic) and we must remain open to the possibility that this may have led to biased results. Online TBL provided dynamic sessions to students and the possibility to engage into meaningful discussions with their classmates, in a context in which close and in-class contacts were abruptly cut. This study should be retaken in a context of higher education 'normality' to assess if the positive acceptance of the methodology holds in face of other online teaching experiences.

Acknowledgements The authors would like to thank Joana Azeredo for submitting the survey to her students.

Author contributions All authors discussed and approved the research design. ECS was responsible for the literature review. Miguel Rocha performed the statistical analysis of data. All authors read and approved the final manuscript.

Funding No funding is declared for this research.

Data availability Data and materials are supplied as supplementary materials at reques 


\section{Declarations}

Conflict of interest The authors declare that they have no conflict of interest.

\section{References}

August, L., Hurtado, S., Wimsatt, L. A., \& Dey, E. L. (2002, June). Learning Styles: Student Preferences versus Faculty Perceptions. In Association for Institutional Research2002 Forum Paper (42nd Canada)

Barone, C. (2011). Some things never change: Gender segregation in higher education across eight nations and three decades. Sociology of Education, 84(2), 157-176.

Bonwell, C. C., \& Eison, J. A. (1991). Active Learning: Creating Excitement in the Classroom. 1991 ASHE-ERIC Higher Education Reports. ERIC Clearinghouse on Higher Education, The George Washington University, One Dupont Circle, Suite 630, Washington, DC 20036-1183.

Braxton, J. M., Milem, J. F., \& Sullivan, A. S. (2000). The influence of active learning on the college student departure process: Toward a revision of Tinto's theory. The Journal of Higher Education, 71(5), 569-590.

Bulanda, J. R., \& Frye, S. (2020). Transforming Introductory Sociology with Team-Based Learning: Sufficient Value and Surmountable Challenge? Teaching Sociology, 48(4), 272-282.

Burhanuddin, Wiyono, B. B., \& Supriyanto, A. (2020, December). Male and female student perceptions on the effectiveness of online courses at University. In 1st International Conference on Information Technology and Education (ICITE 2020) (pp. 617-623). Atlantis Press.

Cabrera, A. F., Crissman, J. L., Bernal, E. M., Nora, A., Terenzini, P. T., \& Pascarella, E. T. (2002). Collaborative learning: Its impact on college students' development and diversity. Journal of College Student Development, 43(1), 20-34.

Cabrera, I., Villalon, J., \& Chavez, J. (2017). Blending communities and team-based learning in a programming course. IEEE Transactions on Education, 60(4), 288-295.

Cheng, C. Y., Liou, S. R., Hsu, T. H., Pan, M. Y., Liu, H. C., \& Chang, C. H. (2014). Preparing nursing students to be competent for future professional practice: Applying the team-based learning-teaching strategy. Journal of Professional Nursing, 30(4), 347-356.

Chyung, S. Y., Roberts, K., Swanson, I., \& Hankinson, A. (2017). Evidence-based survey design: The use of a midpoint on the Likert scale. Performance Improvement, 56(10), 15-23.

Clinton, V., \& Kelly, A. E. (2020). Student attitudes toward group discussions. Active Learning in Higher Education, 21(2), 154-164.

Colbeck, C. L., Cabrera, A. F., \& Terenzini, P. T. (2001). Learning professional confidence: Linking teaching practices, students' self-perceptions, and gender. The Review of Higher Education, 24(2), $173-191$.

Conger, D., \& Long, M. C. (2010). Why are men falling behind? Gender gaps in college performance and persistence. The Annals of the American Academy of Political and Social Science, 627(1), 184-214.

Currey, J., Sprogis, S. K., Burdeu, G., Considine, J., Allen, J., \& Oldland, E. (2018). Students perceive'team-based learning'facilitates development of graduate learning outcomes and professional skills. Journal of Teaching and Learning for Graduate Employability, 9(1), 93-113.

DeMasi, J., Harvan, R. A., \& Luca, M. (2019). Online and In-class team-based learning in undergraduate immunology: A comparative analysis. Medical Science Educator, 29(4), 1193-1199.

Espey, M. (2018). Enhancing critical thinking using team-based learning. Higher Education Research \& Development, 37(1), 15-29.

Frame, T. R., Cailor, S. M., Gryka, R. J., Chen, A. M., Kiersma, M. E., \& Sheppard, L. (2015). Student perceptions of team-based learning vs traditional lecture-based learning. American Journal of Pharmaceutical Education, 79(4), 51.

Freeman, S., Eddy, S. L., McDonough, M., Smith, M. K., Okoroafor, N., Jordt, H., \& Wenderoth, M. P. (2014). Active learning increases student performance in science, engineering, and mathematics. Proceedings of the National Academy of Sciences, 111(23), 8410-8415.

Goh, S. H., Di Gangi, P. M., \& Gunnells, K. (2020). Applying team-based learning in online introductory information systems courses. Journal of Information Systems Education, 31(1), 1-11. 
Gomez, E. A., Wu, D., \& Passerini, K. (2010). Computer-supported team-based learning: The impact of motivation, enjoyment and team contributions on learning outcomes. Computers \& Education, 55(1), 378-390.

Grebennikov, L., \& Skaines, I. (2009). Gender and higher education experience: A case study. Higher Education Research \& Development, 28(1), 71-84.

Gullo, C., Ha, T. C., \& Cook, S. (2015). Twelve tips for facilitating team-based learning. Medical Teacher, 37(9), 819-824.

Haidet, P., Kubitz, K., \& McCormack, W. T. (2014). Analysis of the team-based learning literature: TBL comes of age. Journal on Excellence in College Teaching, 25(3-4), 303.

Hettler, P. L. (2015). Student demographics and the impact of team-based learning. International Advances in Economic Research, 21(4), 413-422.

Hew, K. F., Jia, C., Gonda, D. E., \& Bai, S. (2020). Transitioning to the "new normal" of learning in unpredictable times: Pedagogical practices and learning performance in fully online flipped classrooms. International Journal of Educational Technology in Higher Education, 17(1), 1-22.

Hills, H. (2001). Team-based learning. Gower Publishing.

Hillyard, C., Gillespie, D., \& Littig, P. (2010). University students' attitudes about learning in small groups after frequent participation. Active Learning in Higher Education, 11(1), 9-20.

Hou, H. T., \& Wu, S. Y. (2011). Analyzing the social knowledge construction behavioral patterns of an online synchronous collaborative discussion instructional activity using an instant messaging tool: A case study. Computers \& Education, 57(2), 1459-1468.

Jacobs, J. A. (1996). Gender inequality and higher education. Annual Review of Sociology, 22(1), 153-185.

Johnson, D. W., \& Johnson, R. T. (2009). An educational psychology success story: Social interdependence theory and cooperative learning. Educational Researcher, 38(5), 365-379.

Kauffman, H. (2015). A review of predictive factors of student success in and satisfaction with online learning. Research in Learning Technology, 23, 1

Kubitz, K. A. (2014). The Evidence, Please. In L. K. Michaelsen, A. B. Knight, \& L. Sterling (Eds.) Team-Based Learning: A Transformative Use of Small Groups in College Teaching, (pp. 45-61). VA: Stylus.

Lee, S. J., Ngampornchai, A., Trail-Constant, T., Abril, A., \& Srinivasan, S. (2016). Does a casebased online group project increase students' satisfaction with interaction in online courses? Active Learning in Higher Education, 17(3), 249-260.

Lewis, D., Clontz, S., \& Estis, J. (2021). Team-Based Inquiry Learning. Primus, 31(2), 223-238.

Lundeberg, M. A., \& Moch, S. D. (1995). Influence of social interaction on cognition: Connected learning in science. The Journal of Higher Education, 66(3), 312-335.

Lundin, M., Rensfeldt, A. B., Hillman, T., Lantz-Andersson, A., \& Peterson, L. (2018). Higher education dominance and siloed knowledge: A systematic review of flipped classroom research. International Journal of Educational Technology in Higher Education, 15(1), 1-30.

McLoughlin, C., \& Luca, J. (2006, June). Best practice in online assessment: Principles, processes and outcomes. In EdMedia+ Innovate Learning (pp. 2375-2382). Association for the Advancement of Computing in Education.

Michaelsen, L., \& Sweet, M. (2004). Team-based learning. Sterling.

Moore, A. H., Fowler, S. B., \& Watson, C. E. (2007). Active learning and technology: Designing change for faculty, students, and institutions. Educause Review, 42(5), 42-44.

Moore, C., \& Teather, S. (2013). Engaging students in peer review: Feedback as learning. Issues in Educational Research, 23(2), 196-211.

Nanes, K. M. (2014). A modified approach to team-based learning in linear algebra courses. International Journal of Mathematical Education in Science and Technology, 45(8), 1208-1219.

Opdecam, E., Everaert, P., Van Keer, H., \& Buysschaert, F. (2014). Preferences for team learning and lecture-based learning among first-year undergraduate accounting students. Research in Higher Education, 55(4), 400-432.

Parappilly, M., Woodman, R. J., \& Randhawa, S. (2019). Feasibility and effectiveness of different models of team-based learning approaches in STEMM-based disciplines. Research in Science Education, 1-15.

Parmelee, D. X., \& Hudes, P. (2012). Team-based learning: A relevant strategy in health professionals' education. Medical Teacher, 34(5), 411-413. 
Pires, E. M. S. G., Daniel-Filho, D. A., de Nooijer, J., \& Dolmans, D. H. (2020). Collaborative learning: Elements encouraging and hindering deep approach to learning and use of elaboration strategies. Medical Teacher, 42(11), 1261-1269.

Pirmohamed, S., Debowska, A., \& Boduszek, D. (2017). Gender differences in the correlates of academic achievement among university students. Journal of Applied Research in Higher Education., 9(2), 313-324.

Plump, C. M., \& LaRosa, J. (2017). Using Kahoot! in the classroom to create engagement and active learning: A game-based technology solution for eLearning novices. Management Teaching Review, 2(2), 151-158.

Poirier, C. R., \& Feldman, R. S. (2007). Promoting active learning using individual response technology in large introductory psychology classes. Teaching of Psychology, 34(3), 194-196.

Prince, M. (2004). Does active learning work? A review of the research. Journal of Engineering Education, 93(3), 223-231.

River, J., Currie, J., Crawford, T., Betihavas, V., \& Randall, S. (2016). A systematic review examining the effectiveness of blending technology with team-based learning. Nurse Education Today, 45, 185-192.

Roberson, B., \& Franchini, B. (2014). Effective task design for the TBL classroom. Journal on Excellence in College Teaching, 25.

Samuel, J., \& Hinson, J. (2010, March). Online asynchronous team-based learning: A phased design to enhance student performance. In Society for Information Technology \& Teacher Education International Conference (pp. 2366-2370). Association for the Advancement of Computing in Education.

Saunders, G., \& Klemming, F. (2003). Integrating technology into a traditional learning environment: Reasons for and risks of success. Active Learning in Higher Education, 4(1), 74-86.

Stump, G. S., Hilpert, J. C., Husman, J., Chung, W. T., \& Kim, W. (2011). Collaborative learning in engineering students: Gender and achievement. Journal of Engineering Education, 100(3), 475-497.

Styron, J. L., \& Styron, J. L. (2014). Using a common pedagogy across multiple disciplines to improve student learning. Systemics, Cybernetics and Informatics, 12(6).

Swanson, E., McCulley, L. V., Osman, D. J., Scammacca Lewis, N., \& Solis, M. (2019). The effect of team-based learning on content knowledge: A meta-analysis. Active Learning in Higher Education, 20(1), 39-50.

Sweet, M., \& Michaelsen, L. K. (2012). Team-based learning in the social sciences and humanities: Group work that works to generate critical thinking and engagement. Stylus Publishing.

Taylor, L., McGrath-Champ, S., \& Clarkeburn, H. (2012). Supporting student self-study: The educational design of podcasts in a collaborative learning context. Active Learning in Higher Education, 13(1), 77-90.

Tsai, C. W. (2011). Achieving effective learning effects in the blended course: A combined approach of online self-regulated learning and collaborative learning with initiation. Cyberpsychology, Behavior, and Social Networking, 14(9), 505-510.

Travis, L. L., Hudson, N. W., Henricks-Lepp, G. M., Street, W. S., \& Weidenbenner, J. (2016). Teambased learning improves course outcomes in introductory psychology. Teaching of Psychology, 43(2), 99-107.

Turney, C. S. M., Robinson, D., Lee, M., \& Soutar, A. (2009). Using technology to direct learning in higher education: The way forward? Active Learning in Higher Education, 10(1), 71-83.

Vuopala, E., Hyvönen, P., \& Järvelä, S. (2016). Interaction forms in successful collaborative learning in virtual learning environments. Active Learning in Higher Education, 17(1), 25-38.

Wallace, M. L., Walker, J. D., Braseby, A. M., \& Sweet, M. S. (2014). “ Now, what happens during class?" using team-based learning to optimize the role of expertise within the flipped classroom. Journal on Excellence in College Teaching, 25, 1.

Publisher's note Springer Nature remains neutral with regard to jurisdictional claims in published maps and institutional affiliations. 


\section{Authors and Affiliations}

\section{Elsa Costa e Silva ${ }^{1}$ (D) Teresa Lino-Neto ${ }^{2}$ (D) $\cdot$ Eugénia Ribeiro $^{3}$ (D) Miguel Rocha ${ }^{4}$ (D) Manuel João $\operatorname{Costa}^{5}$ (D)}

1 Communication Sciences Department/Communication and Society Research Center, University of Minho, Campus de Gualtar, 4710-057 Braga, Portugal

2 BioSystems and Integrative Sciences Institute (BioISI), Plant Functional Biology Centre, University of Minho, Campus de Gualtar, 4710-057 Braga, Portugal

3 Psychology Research Center, School of Psychology, University of Minho, Campus de Gualtar, 4710-057 Braga, Portugal

4 Center of Biological Engineering, University of Minho, Campus de Gualtar, 4710-057 Braga, Portugal

5 Division Life and Health Sciences Research Institute (ICVS), School of Medicine, University of Minho, Campus de Gualtar, 4710-057 Braga, Portugal 